\title{
MODELLING AND OPTIMISATION FOR DEVELOPMENT OF MULTI-SERVICE-LIFE PRODUCTS
}

\author{
XING, K.
}

Abstract: Based on the concepts of "3Rs" (Reduce, Reuse, and Recycle), it is in the interest of sustainability that a product is designed for serving multiple life cycles. This paper presents a method for the modelling and design optimisation of product fitness for MLS. The proposed mathematical model uses three key indicators, namely Compatibility to Generational Variety (CGV), Fitness for Extended Utilisation (FEU), and Life-cycle Oriented Modularity (LOM), to capture and represent a product's functional, physical, and structural characteristics for the ease of MLS. Based on these three indicators, an objective function is formulated for design optimisation. Genetic Algorithms techniques are adopted to enable the search mechanism for optimal functional, physical, and structural configurations of a product under a given $M L S$ scenario. A case example of a solar heating system is used to demonstrate the implementation of the methodology.

Key words: Product Upgradability, Modelling, Design Optimisation, Service-life Extension, Reuse, Remanufacture
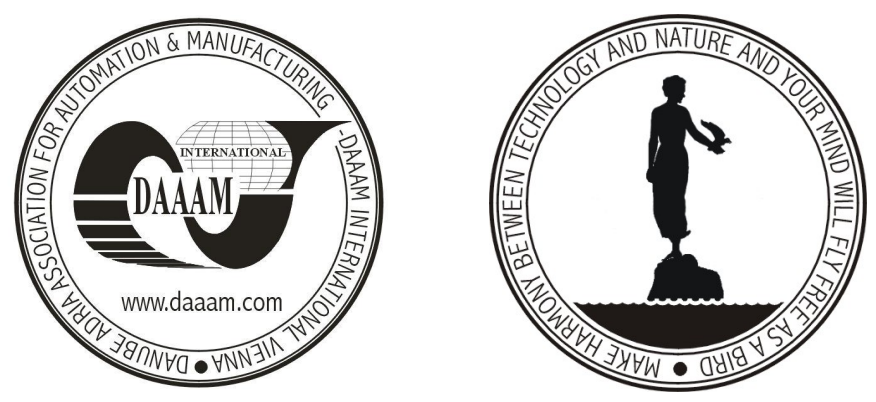

Authors' data: Dr. Xing, K[e], University of South Australia, Mawson Lakes Campus, Mawson Lakes, Adelaide, SA5074 Australia, ke.xing@unisa.edu.au

This Publication has to be referred as: Xing, K. (2007). Modelling and Optimisation for Development of Multi-Service-Life Products, Chapter 48 in DAAAM International Scientific Book 2007, B. Katalinic (Ed.), Published by DAAAM International, ISBN 3-901509-60-7, ISSN 1726-9687, Vienna, Austria DOI: $10.2507 /$ daaam.scibook.2007.48 